\title{
Occurrence of non-cultivable acid-fast bacilli in the environment and their relationship to M. leprae
}

\author{
J KAZDA \\ Department of Microbial Ecology, Research Institute Borstel, \\ D-2061 Borstel, Federal Republic of Germany
}

Using the mouse footpad technique devised by Shepard (1) for cultivation of $M$. leprae, we have been able to isolate non-cultivable acid-fast bacilli (NC AFB) from environmental samples. NC AFB could first be demonstrated in samples originating from former leprosyendemic regions in Norway (2). Samples collected in present leprosy-endemic areas (Ivory Coast, India, Peru, Pnrtugal) also yielded NC AFB.

The isolated NC AFB were shown to be polymorphous acid-fast rods which, similar to M. leprae, multiply to a limited extent in the footpads of mice, even after passage. All attempts to culture them on the common culture media such as Löwenstein-Jensen and Middlebrook medium failed (2). On the basis of their morphological properties and pronounced acid-fastness the isolants have tentatively been classed with the genus

Materials and Methods

So far 729 samples of sphagnum, water, and soil have been collected and examined for NC AFB. The samples originated both from leprosyendemic countries with varying leprosy morbidity and from regions where authochtonous leprosy has disappeared for many centuries (Germany, Sweden, Scotland). Table 2 shows the number of samples from various locations.

The sphagnum specimens were examined for NC AFB as previously reported (2). Water samples of $400-800 \mathrm{ml}$ were filtered through a membrane filter (pore size $1.2 \mu \mathrm{m}$ ) using a pneumatic pump (Antlia SP 050/2 produced by Schleicher \& Schüll, Germany). After addition of $2 \mathrm{ml}$ of a $0.1 \%$ albumin solution the membrane filters were homogenized for $20 \mathrm{sec}$ at $20000 \mathrm{rmp}$ in an Ultra Turrax type TP 18/2 (Janke \& Kunkel). The suspension was left standing for $2 \mathrm{~min}$; then the supernatant was poured off and centrifuged for $30 \mathrm{~min}$ at 3000 rpm. Prior to inoculation the sediment was resuspended in $1 \mathrm{ml}$ of a $0.1 \%$ albumin solution.

The soil and vegetation samples were homogenized in a mortar 
with 5 times their volume of a $0.85 \%$ saline solution; the supernatant was poured off, centrifuged for $30 \mathrm{~min}$ at $3000 \mathrm{rpm}$, and the sediment resuspended in $1 \mathrm{ml}$ of a $0.1 \%$ albumin solution. $0.03 \mathrm{ml}$ of each suspension were injected into both hind footpads of 10 female mice of the inbred strain NMRI SPF. The footpads were examined for $\mathrm{NC} A F B$ 6, 9, 12, 18 and 24 months after inoculation. We used a method by which the tissue and the bone parts of the footpads were obtained under sterile conditions and homogenized in an Ultra Turrax type TP $18 / 2 \mathrm{n}$ at $20000 \mathrm{rmp}$. The AFB in the supernatant were counted (2). Sterile conditions are essential for the demonstration of NC AFB to prevent contamination with cultivable AFB from the skin surface of the mouse footpads or from non-sterile instruments.

Simultaneously, each mycobacterial suspension was cultured for 6 months on Löwenstein-Jensen and Middlebrook 7H10 medium in order to assess its "non-cultivability". When growth occurred, the samples were discarded. The mycobacterial suspensions harvested from mouse footpads and containing more than $10000 \mathrm{AFB}$ per ml were checked for their ability to multiply on the so-called sphagnum medium (SNS). This substrate is obtained from an environmental medium in which $\mathrm{NC} \mathrm{AFB}$ abound. An investigation conducted in a former leprosy-endemic region (Naustdal, West Norway) had provided information on the habitats and niches offering optimum growth conditions for sphagna harbouring numerous NC AFB (3). The results of this study indicate that the largest numbers of NC AFB are to be found on the surface of the so-called grey layer of the sphagnum vegetation which contains the nutrients required for mycobacterial growth. This "nutrient layer" was obtained by centrifugation of sphagnum grown artificially in glass houses for 4 to 6 months. Through filtration (membrane filter, pore size $0.2 \mu \mathrm{m}$ ) followed by radiation with gamma rays of the freeze-dried material, a sterile substrate is obtained. It represents a complex medium; in addition to autolytic products released when sphagnum becomes peaty, it contains exogenous products of numerous fungi. Analyses revealed the presence of at least 17 amino acids (glutamic acid, asparagine, serine and glycine predominate), a number of carbohydrates (fructose, galactose and arabinose), and several steroids, mainly cholesterol, campasterol and $\beta$-sitosterol.

$1 \mathrm{ml}$ of bidistilled water was added per $5 \mathrm{mg}$ of the substrate and the solution obtained was used as culture medium without addition of any further substances. The results attained so far suggest that M. leprae multiplies by 2 powers $\left(10^{4}-10^{6}\right)$ on this medium within 4 to 5 months. The AFB grown on this medium exhibit the distinct biochemical properties of M. leprae (positive Dopa and pyridine reaction) as can be seen from Table 1. Multiplication of NC AFB from $10^{3}$ to $10^{6}$ in the sphagnum medium has been noted, with a generation time of 8.1 days. 
Table 1. The use of sphagnum nutritive substrate for dopa oxidase and pyridine reaction in Mycobacterium leprae.

\begin{tabular}{lccccc}
\hline $\begin{array}{c}\text { Biopsy } \\
\text { Material }\end{array}$ & $\begin{array}{c}\text { Incubation } \\
\text { Time }\end{array}$ & $\begin{array}{c}\text { Multiplication } \\
\text { Rate }\end{array}$ & $\begin{array}{c}\text { AFB } \\
\text { Concentration }\end{array}$ & $\begin{array}{c}\text { Dopa } \\
\text { nxidase }\end{array}$ & $\begin{array}{c}\text { Pyridine } \\
\text { Extraction }\end{array}$ \\
\hline M.leprae KA 104 & 5 Months & $10^{4}$ to $10^{6}$ & $4,3 \times 10^{7}$ & + \\
M.leprae HH 101 & 5 Months & $10^{4}$ to $10^{6}$ & $2,8 \times 10^{7}$ & + \\
M.leprae HH 101 & 5 Months & $10^{3}$ to $10^{6}$ & $3,8 \times 10^{7}$ & + \\
M.leprae P 350 & 4 Months & $10^{4}$ to $10^{6}$ & $5,7 \times 10^{7}$ & + \\
M.leprae P 350 & 5 Mnnths & $10^{3}$ to $10^{6}$ & $4,8 \times 10^{7}$ & + \\
\hline
\end{tabular}

The differentiation of the environmental NC AFB has been performed as follows:

1. Biochemical tests: Dopa test (4) and pyridine test (according to the method modified by McCormick and Sanches) (5). The AFB tested had been grown in the sphagnum medium or harvested from the spleen of armadillos.

2. Biological differentiation: Mouse footpad technique: Limited multiplication in the footpads of mice was observed after inoculation. The NC AFB were shown to be non-pathogenic for mice which allows to differentiate them from M. lepraemurium. I.V. infection of armadillos resulted in bacterial multiplication in the organs of these animals.

\section{Results}

Since our experiments are still under way, only preliminary results are presented in this paper.

Of the 729 samples collected, 273 originated from former leprosy-endemic regions in Norway (7), 157 from present leprosyendemic regions (Ivory Coast, Portugal, Peru, India), and 67 from an area in Louisiana, USA, where a "leprosy-like disease" in armadillos has been observed. For comparison, 232 samples were collected in countries where endemic leprosy had disappeared (Germany, Scotland, Sweden). The results are presented in Table 2. 
Table 2. Examination of NC AFB: Preliminary results.

\begin{tabular}{|c|c|c|c|}
\hline \multirow[b]{2}{*}{ Region } & \multicolumn{2}{|c|}{ Specimens examined } & \multirow[b]{2}{*}{ Per cent } \\
\hline & Total & NC AFB positive & \\
\hline Norway & 273 & 90 & 32.9 \\
\hline Ivory Coast & 71 & 17 & 23.9 \\
\hline Portugal & 36 & 20 & 55.6 \\
\hline Peru & 30 & 12 & 40.0 \\
\hline India & 20 & 6 & 30.0 \\
\hline Louisiana/USA & 67 & 17 & 25.4 \\
\hline Sweden & 40 & 0 & 0 \\
\hline Scotland & 77 & 0 & 0 \\
\hline Germany & 115 & 0 & 0 \\
\hline
\end{tabular}

A relatively high proportion of the samples (23-55\%) originating from former and present leprosy-endemic regions were positive for NC AFB, while no NC AFB were detected in the samples from countries where leprosy has disappeared. Also the samples from Louisiana did yield NC AFB.

\section{Differentiation of NC AFB}

BEHAVIOUR IN THE FOOTPADS OF MICE AFTER EXPERIMENTAL INOCULATION

Apart from a local swelling during the first few days after injection of 162 strains, no clinical changes were observed on the footpads, nor could any histological changes characteristic of mycobacteriosis be seen in the organs of the mice. The AFB harvested from footpads continued to multiply by 2 to 3 powers (up to 106) in further passages, whereas attempts to culture them on the common media were unsuccessful. 
INFECTION OF ARMADILLOS (DASYPUS NOVEMCINCTUS)

So far 11 strains of NC AFB have been tested by infection of armadillos. The results obtained with 4 strains have been evaluated. Two strains could not be differentiated from M. leprae, viz.:

Strain Su 1 originating from a former leprosy-endemic region in Norway (Sunde, Naustdal district) where it was isolated in 1977 from Sphagnum rubellum. After inogulation into the footpads of mice, it multiplied up to $2.3 \times 10^{5}$ within 12 months. The AFB harvested from the footpads were incubated for 9 months in the sphagnum medium. Then a bacferial suspension recovered from this medium and containing $9.8 \times 10^{5} \mathrm{AFB}$ was injected intravenously into an armadillo. Blood samples were withdrawn and examined 10 and 16 months after infection. AFB were seen in the macrophages. At autopsy 17 months after infection the animal presented enlargement of the liver and spleen, but no lesions were visible. Large numbers of AFB could be demonstrated in both organs by differential and densitygradient techniques (4). The AFB were positive in the Dopa test, with a maximum absorption between 480-530 nm, characteristic of $\mathrm{M}$. leprae. They were also destained by pyridine, as is the case with M. leprae.

Strain Fi 38, isolated in 1978 from surface water of a leprosyendemic region (Ivory Coast) exhibited similar properties. It originated from a $300 \mathrm{ml}$ water sample collected from a pond near Baigne (Adzope district). After inoculation into the footpads of mice it multiplied up to $4.4 \times 10^{5}$. The $A F B$ recovered from the footpads were incubated in SNS for 4 and 5 months. Then an armadillo was infected intravenously with a suspension containing $1.18 \times 10^{7} \mathrm{AFB}$ and later again with an inoculum of $9.30 \times 10^{\circ}$. The animal died after 12 months. The post-mortem examination revealed a considerable enlargement of liver and spleen in which AFB could be demonstrated. But no other lesions were seen in the organs. The Dopa and pyridine reactions were positive, as in the case with M. leprae.

Two other strains of NC AFB showed a behaviour different to that of M. leprae:

Strain So 5 was isolated in 1976 from sphagnum collected on the isle of Sotra near Bergen. It was passage twice in the footpads of mice where it multiplied up to $1.5 \times 10^{6}$ within 6 months. A suspension containing $7.1 \times 10^{5} \mathrm{AFB}$ was injected intravenously into an armadillo and simultaneously incubated in SNS. After 7 months of incubation the animal was again infected with $5.4 \times 10^{5} \mathrm{AFB}$ recovered from the SNS. The animal died 12 months after the first infection. A severe mycobacteriosis was seen at autopsy. Granulomas were recognized in the lungs, liver, spleen and kidneys. The histological examination revealed confluent granulomas of epitheloidal cells, macrophages, monocytes, and numerous polygrainous cells of the Langhans type in all parenchymatous organs. As in similar 
cases of mycobacterioses of such productive character, a large proportion of AFB lost their acid-fastness due to phagocytosis. However, solidly stained AFB could be demonstrated in the liver and spleen after separation using differential and density-gradient techniques. The Dopa and pyridine tests were negative.

Strain Fi 31 was isolated from well water collected on the premises of the leprosarium at Adzope (Ivory Coast). Eleven months after footpad inoculation, $2.2 \times 10^{5}$ AFB were recovered and incubated for 4 months in SNS. A bacterial suspension harvested from this medium and containing $4.04 \times 10^{5} \mathrm{AFB}$ was then injected intravenously into an armadillo. After repeated blood examinations had revealed $A F B$ in macrophages, the animal was sacrificed.(8). At autopsy the animal presented enlargement of 1 iver and spleen and large numbers of $\mathrm{AFB}$ in both organs. AFB were demonstrated in the spleen by differential and density-gradient techniques. The Dopa and pyridine tests were negative.

Further experiments aimed at differentiating the NC AFB isolated are under way.

\section{Discussion}

The fact that NC AFB resembling M. leprae have been isolated from the environment raises the following questions:

- What is the role being played by these NC AFB (which are capable of multiplying in environmental substrates) in the etiology of leprosy?

- Will continual ingestion of these AFB via drinking water or by direct contact with the environment lead to the outbreak of leprosy?

In this connection I remind you of the findings of Dr. Sand from the leprosarium Reitgjaerdet in Norway. At the 2nd leprosy congress held in Bergen in 1910 he postulated that leprosy is not transmitted by direct contact, but indirectly through a natural medium (soil) in which the causative organism undergoes a developmental stage.

The AFB differing from M. leprae in some of their properties might be of significance as co-factors in the genesis of leprosy, or possibly lead to subclinical leprosy.

\section{Acknowledgements}

The author would like to thank Dr. L. M. Irgens from the University of Bergen, Norway, and Prof. Dr. K. Müller, University of Kiel, Germany, for their co-operation in field trials. Thanks are also 
extended to Dr. W. Kirchheimer, USPHSH Carville/USA for his help in the studies carried out in Louisiana.

\section{References}

1 Shepard CC. Multiplication of Mycobacterium leprae in the footpad of the mouse. Int J Lepr, 1962, 30, 291.

2 Kazda J, Irgens LM, Müller K. Isolation on non-cultivable acidfast bacilli in sphagnum and moss vegetation by footpad technique in mice. Int $\mathrm{J}$ Lepr, 1980, 48, 1.

3 Irgens LM, Kazda J, Müller K. Conditions relevant to the occurrence of acid-fast bacilli in sphagnum vegetation. Acta path Microbiol Scand, Sect B, 89, 41 .

4 Prabhakaran K, Harris EB, Kirchheimer WF. Hypopigmentation of skin lesions in leprosy and occurrence of 0-diphenoloxidase in Mycobacterium leprae. Pigment cell, Vol. 3. Basel: S. Karger.

5 McCormick TG, Sanches RM. Pyridine extractability of acidfastness from Mycobacterium leprae. Int J Lepr, 1979, 47, 495.

6 Kirchheimer WF, Storrs EE. Attempts to establish the armadillo (Dasypus novemcinctus Linn.) as a model for the study of leprosy. Int J Lepr, 1971, 39, 693.

7 Irgens LM. Leprosy in Norway. Lepr Rev, 1980, 51, Suppl 1.

8 Kirchheimer WF. Advances in biomedical leprosy research. Jap J Lepr, 1980, 49, 209.

9 Sand A. Geschiet die Ansteckung der Lepra durch unmittelbare Ubertragung? Mitteil. u. Verhandl. II. Leprakonferenz, Bergen 3, 39. 